\title{
May a correlation exist between preoperative depression and anxiety levels and wound healing complications following reduction mammoplasty in the overweight female?
}

\author{
Aşırı kilolu kadınlarda preoperatif depresyon ve anksiyete düzeyleri ile küçültme \\ mammoplasti sonrası yara iyileşme komplikasyonları arasında ilişki olabilir mi?
}

\author{
Mehmet ÇEBER
}

\section{ABSTRACT}

The aim of this study was to determine the relationship between preoperative levels of depression and anxiety, and postoperative wound healing complications and the duration of hospital stay among overweight or obese women with macromastia who underwent reduction mammoplasty. Fifty overweight or obese women with symptomatic macroplastia who underwent bilateral reduction mammoplasty at our department were included in this prospectively designed study. Preoperative levels of depression were evaluated using Hamilton Depression Scale (HDS) and Hamilton Anxiety Scale (HAS). Patients mean preoperative BMI ranged from 25.82 to $46.75 \mathrm{~kg} / \mathrm{m}^{2}$, with a mean of $34.36 \pm 6.68$ $\mathrm{kg} / \mathrm{m}^{2}$. Total weight of the specimens resected from both breasts ranged from 1500 to $3600 \mathrm{~g}$, with a mean of $2824 \pm 543.63 \mathrm{~g}$. The mean HAM-D score of the patients was $14.74 \pm 12.54$, the mean HAM-A score was 12.30 \pm 9.62 . Postoperative minor surgical complications occurred in 15 (30\%) patients. Any major complication was not developed in any patient. In terms of the development of complications any statistically significant difference was not observed between depressive $(n=28)$ and non-depressive patients $(n=22)$, and between preoperatively anxious $(n=34)$ and non-anxious patients $(n=16)(p=0.32$ and $p=0.597$, respectively). In terms of the the duration of hospital stay, present study showed significant differences between depressive and non-depressive and between preoperatively anxious and non-anxious patients $(p<0.001$ and $p<0.01$, respectively). Overweight or obese women with symptomatic macromastia who applied to the hospital for reduction mammoplasty had mild depression and minor anxiety preoperatively. As the severity of preoperative depression, and anxiety increases, postoperative surgical wound healing complications and duration of hospital stay increase.

Keywords: Depression, anxiety, macromastia, reduction mammoplasty, wound healing complication öz

Çalışmanın amacı küçültme mammoplasti uygulanan semptomatik makromastili, aşırı kilolu ve obez kadınlarda preoperatif depresyon ve anksiyete düzeyleri ile postoperatif yara iyileşme komplikasyonları ve hastanede yatış süreleri arasındaki ilişkiyi incelemektir. Çalışmamı meme küçültme ameliyatı için başvuran, aşırı kilolu veya obez, semptomatik makromastili 50 kadın hastada prospektif olarak gerçekleştirilmiştir. Küçültme mammoplasti uygulanan hastalarda preoperatif depresyon düzeyleri Hamilton Depresyon Derecelendirme Ölçeği (HAM-D) ile, preoperatif anksiyete düzeyleri Hamilton Anksiyete Derecelendirme Ölçeği (HAM-A) ile değerlendirilmiştir. Hastaların ortalama vücut kitle indeksi ameliyat öncesi $34,36 \pm 4,68 \mathrm{~kg} / \mathrm{m}^{2}(25,82 \mathrm{~kg} /$ $\mathrm{m}^{2}-46,75 \mathrm{~kg} / \mathrm{m}^{2}$ ) idi. Eksize edilen meme dokusu miktarı ortalama $2824 \pm 543,63 \mathrm{~g}(1500-3600 \mathrm{~g})$ idi. Hastaların HAM-D puanı ortala-

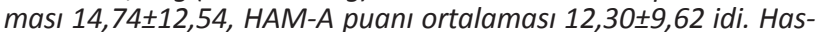
taların 15'inde (\%30) postoperatif minor cerrahi komplikasyonlar gelişti. Hiçbir hastada major komplikasyon gelişmedi. Depresyon bulguları olan $(n=28)$ ve depresyon bulguları olmayan $(n=22)$ olan hasta grupları arasında komplikasyon gelişimi açısından istatistiksel olarak anlamlı farklılık gözlenmedi $(p=0,32)$. Preoperatif anksiyete bulguları olan $(n=34)$ ve anksiyete bulguları olmayan $(n=16)$ hasta grupları arasında komplikasyon gelişimi açısından istatistiksel olarak anlamlı farklılık gözlenmedi $(p=0,597)$. Preoperatif depresyon bulguları olan $(n=28)$ ve depresyon bulguları olmayan $(n=22)$ hasta grupları arasında hastanede yatıs süreleri açısından istatistiksel olarak anlamlı farklılık gözlendi $(p<0,001)$. Preoperatif anksiyete bulguları olan $(n=34)$ ve anksiyete bulguları olmayan $(n=16)$ hasta grupları arasında hastanede yatış süreleri açısından istatistiksel olarak anlamlı farklılık gözlendi $(p<0,01)$. Meme küçültme ameliyatı olmak için başvuran semptomatik makromastili, aşırı kilolu ve obez hastalar preoperatif dönemde hafif derecede depresyona ve minor anksiyeteye sahiptiler. Hastalarda preoperatif depresyon ve anksiyete düzeyleri arttıkça postoperatif yara iyileşme komplikasyonları ve hastanede yatış süreleri istatistiksel olarak anlamlı olmamakla birlikte artmıştır.

Anahtar kelimeler: Depresyon, anksiyete, makromasti, küçültme mammoplasti, yara iyileşme komplikasyonu

Received: 18.04 .2016

Accepted: 06.06.2016

Namik Kemal University, Faculty of Medicine Department of Plastic, Reconstructive and Aesthetic Surgery

Yazışma adresi: Mehmet Çeber, Namik Kemal University, Faculty of Medicine Department of Plastic, Reconstructive and Aesthetic Surgery, Tekirdağ

e-mail: mdceber@yahoo.com 


\section{Giriş}

Makromasti memelerin aşırı büyüklüğüne bağlı meme ağrısı, sırt ağrısı, boyun ağrısı, omuz ağrısı, sütyen askısı basısına bağlı omuzlarda çöküklük, intertriginöz kızarıklıklar, postür değişiklikleri ve spor yapmada zorluklar gibi bazı yakınmalara neden olmasının yanı sıra kişilerin emosyonel durumlarını da olumsuz etkileyen bir rahatsızıktır.

Semptomatik makromastili kadınların birçoğu aşırı kilolu veya obezdir. Makromastili hastalarda postoperatif komplikasyonların oluşmasından sıklıkla obezite sorumlu tutulduğu için plastik cerrahlar bu hastaları ameliyat etmekten kaçınırlar ve hastalardan cerrahi öncesi kilo vermelerini isterler ${ }^{1-2}$. Ancak makromastinin ve aşırı kiloların neden olduğu fiziksel aktivite azlığına bağlı spor yapmaktaki zorluklar çoğu kez hastaların preoperatif kilo vermesini olası kılmaz. Ayrıca bu hastaların estetik kaygıdan çok yaşam kalitesini düşüren ağrı, anksiyete ve depresyon, kendilerine güvenlerinin ve saygılarının azalması gibi yakınmaları de vardır ki bu emosyonel yakınmalar çoğu kez fiziksel semptomlardan daha yıkıcı olabilir.

Kadınlarda meme hacmindeki artış ile depresyon semptomları arasında ilişki olduğu ${ }^{3-5}$ ve estetik amaçlı küçültme mammoplasti uygulanan kadınların $1 / 3^{\prime}$ inde operasyondan önce anksiyete, depresyon ve beden saygısında azalma olduğu belirtilmiştir ${ }^{6-9}$. Diğer taraftan estetik operasyonlar öncesi hastalarda depresyon, anksiyete gibi emosyonel sorunların, operasyon sonrası iyileşmenin gecikmesine, komplikasyon artışına ve ameliyatın sonucundan memnuniyetsizliğe yol açtığı gösterilmiştir ${ }^{10-11}$.

Küçültme mammoplasti sonrası gelişen komplikasyonlardan sıklıkla obezite sorumlu tutulurken hastaların preoperatif emosyonel durumlarının komplikasyon gelişimindeki rolü hep göz ardı edilmiştir. Bu nedenle hastaların ameliyat öncesi psikiyatrik yönden değerlendirilmesi önemli gözükmektedir.

Bu çalışma, meme küçültme ameliyatı uygulanan semptomatik makromastili, aşırı kilolu ve obez ka- dınlarda preoperatif depresyon ve anksiyete düzeyleri ile postoperatif yara iyileşme komplikasyonları ve hastanede yatış süreleri arasında bir ilişki olup olmadığını belirlemek amacıyla planlanmıştır.

\section{GEREÇ ve YÖNTEM}

Çalışma Etik Kurul izni alındıktan sonra Mayıs 2013Ocak 2016 tarihleri arasında hastanemize meme küçültme ameliyatı için başvuran, 18 yaş ve üstü, ameliyat öncesi vücut kitle indeksi $25 \mathrm{~kg} / \mathrm{m}^{2 \prime}$ den yüksek olan, okuma yazma bilen, soruları yanıtlayabilecek yeterliliğe sahip ve araştırmaya katılmaya gönüllü, semptomatik makromastili 50 kadın hastada prospektif olarak gerçekleştirilmiştir. Küçültme mammoplasti uygulanan hastalarda preoperatif depresyon düzeyleri Hamilton Depresyon Derecelendirme Ölçeği (HAM-D) ile ve preoperatif anksiyete düzeyleri Hamilton Anksiyete Derecelendirme Ölçeği (HAM-A) ile değerlendirilmiştir.

\section{Hamilton Depresyon Derecelendirme Ölçeği} (HAM-D): Depresif belirtileri olan kişilerde depresyonun düzeyini ve şiddet değişimini ölçmek için uygulanan, değerlendiricinin derecelemesine dayanan, 17 soruluk bir testtir. M. Hamilton ve B. W. Williams tarafından 1978 yılında geliştirilmiştir ${ }^{12}$. Ölçeğin uykuya dalma güçlüğü, gece yarısı uyanma, sabah erken uyanma, somatik semptomlar, genital semptomlar, zayıflama ve içgörü ile ilgili maddeleri 0-2, diğer maddeleri 0-4 arasında derecelendirilmiştir. Yapılan derecelendirmenin toplanmasıyla 0 ile 53 arasında değişen ölçek toplam puanı elde edilmektedir ve puandaki artış depresyonun şiddetindeki artışa işaret etmektedir. Sıfır-yedi arası puan depresyon olmadığını, 8-15 arası puan hafif derecede depresyonu, 1628 arası puan orta derecede depresyonu, 29 ve üzeri puanlar ağır derecede depresyonu göstermektedir. Ölçeğin Türk kültüründeki geçerlik ve güvenirlik çalışması Akdemir ve ark. ${ }^{13}$ tarafından yapılmıştır.

\section{Hamilton Anksiyete Derecelendirme Ölçeği} (HAM-A): Hamilton tarafından 1959 yılında bireylerdeki anksiyete düzeyini ve belirti dağılımını belirlemek ve şiddet değişimini ölçmek amacıyla gelişti- 
M. Çeber, May a correlation exist between preoperative depression and anxiety levels and wound healing complications following reduction mammoplasty in the overweight female?

rilmiştir ${ }^{14}$. Anksiyetenin hem psişik hem de fiziksel belirtilerini sorgulayan toplam 14 soru içermektedir. Her soruya 0-4 arasında puan verilerek, her maddeden elde edilen puan toplanarak toplam puan elde edilir. Ölçeğin toplam puanı 0-56 arasında değişmektedir. Toplam puanlar hesaplanmakta, 0-5 puan anksiyetenin olmadığını, 6-14 puan minör anksiyete (hafif orta) 15 puan ve üstü majör anksiyeteyi (ağır) göstermektedir. Ölçekte belirtilerin varlığı ve şiddeti görüşmeci tarafından değerlendirilir. Türkiye için geçerlik-güvenilirlik çalışması Yazıcı ve ark. ${ }^{15}$ tarafından yapılmıştır.

Ameliyat sonrası hastaların dosyaları incelenerek hastaların yaşları, ameliyat öncesi kiloları, boylar, vücut kitle indeksleri (VKi), ek hastalıkları, gelişen komplikasyonlar, hastanede yatış süreleri, komplikasyonların nasıl tedavi edildiği ve ameliyattan dosya inceleme gününe kadar geçen süreler kaydedildi. Hastaların preoperatif depresyon ve anksiyete düzeyleri ile yara iyileşme komplikasyon gelişimi ve hastanede yatış süreleri arasında bir ilişki olup olmadığı istatistiksel olarak değerlendirildi.

\section{Verilerin Değerlendirilmesi}

İstatistiksel analiz için PASW $^{\circledR}$ Statistics 18 programı (SPSS Inc., Chicago, IL, USA) kullanıldı. Çalışma verileri değerlendirilirken tanımlayıcı istatistiklerin (Yüzde, Frekans, Ortalama, Standart Sapma, Minimum, Maksimum) yanı sıra kategorik verilerin karşılaştırılmasında ki-kare testi kullanıldı. $p<0,05$ değeri istatistiksel olarak anlamlı kabul edildi.

\section{BULGULAR}

Hastaların yaş ortalaması 41,66 $\pm 11,50$ (en düşük 18, en yüksek 61) idi. Hastaların ortalama VKi ameliyat öncesi $34,36 \pm 4,68 \mathrm{~kg} / \mathrm{m}^{2}$ (minimum 25,82 kg/m², maksimum $46,75 \mathrm{~kg} / \mathrm{m}^{2}$ ) idi. Eksize edilen meme dokusu miktarı ortalama 2824 $\pm 543,63$ g (1500-3600 g) idi (Tablo 1).

Hastaların 5'inin $(\% 8,9)$ hipertansiyon, 3'ünün $(\% 6,7)$ diyabetes mellitus, $5^{\prime}$ inin $(\% 11,1)$ romatoid artrit, 9'unun $(\% 17,8)$ depresyon, 3'ünün $(\% 6,7)$ diğer (astım, psöriasis, hipotiroidi) hastalıkları vardı. Romatoid artritli 5 hasta ve psöriasisli 1 hasta metotreksat kullanıyordu. Bu hastalar metotreksat tedavisine başladıktan sonra kilo aldıklarını ve memelerinin büyüdüğünü belirttiler. Depresyon tanısı alan hastaların 9'u da antidepresan ilaç kullanıyordu.

Tablo 1. Sosyodemografik özellikler.

\begin{tabular}{|c|c|c|c|}
\hline & Ort. $\pm S S$ & Minimum & Maksimum \\
\hline Yaş & $41,66 \pm 11,50$ & 18 & 61 \\
\hline $\begin{array}{l}\text { Vücut kitle indeksi } \\
\left(\mathrm{kg} / \mathrm{m}^{2}\right)\end{array}$ & $34,36 \pm 4,68$ & 26 & 47 \\
\hline $\begin{array}{l}\text { Eksize edilen meme } \\
\text { ağırlığı (g) }\end{array}$ & $2824 \pm 543,63$ & 1500 & 3600 \\
\hline HAM-D ölçeği puanı & $14,74 \pm 12,54$ & 2 & 41 \\
\hline HAM-A ölçeği puanı & $12,30 \pm 9,62$ & 2 & 35 \\
\hline Yatış süresi (gün) & $8,52 \pm 4,32$ & 5 & 28 \\
\hline
\end{tabular}

Hastaların 15'inde (\%30) postoperatif minor komplikasyonlar gelişti. En sık görülen komplikasyonlar 8 memede (\%16) sütür hattında yara ayrışması, 2 memede (\%4) seroma oluşumu, 1 memede (\%2) yüzeyel desquamasyon, 2 memede (\%4) areolanın marginal nekrozu, 2 memede (\%4) yüzeyel hematom idi. Yara ayrışmaları günlük yara bakımları ile takip edildi, bunlardan 2'sinde sekonder sütür ile iyileşme sağlanırken 6'sı sekonder epitelizasyonla iyileşti. Seroma oluşan hastalar periyodik olarak takip edildi, herhangi bir cerrahi girişime gerek olmadı. Yüzeyel desquamasyon gelişen hasta pansumanlarla sekonder olarak epitelize olarak iyileşti. Areolada marginal nekroz gelişen 2 hasta yatırılarak günlük debridman ve pansumanlarla takip edildikten sonra revizyon cerrahisi ile tedavi edildi. Hematom gelişen 2 hasta drenaj ve pansumanlarla takip edildikten sonra sekonder olarak iyileşti. Derin ven trombozuna bağlı pulmoner emboli, kardiyopulmoner komplikasyonlar veya sepsis gibi major komplikasyonlar görülmedi.

Otuz dokuz ve altı yaş grubundaki hastalarda $(n=25)$ 3 hastada (\%12) komplikasyon gelişirken, 40 ve üstü yaş grubundaki hastalarda $(n=25) 12$ hastada (\%48) komplikasyon gelişmişti (Tablo 2). Her iki grup arasında komplikasyon gelişimi açısından istatistiksel olarak anlamlı farklılık olduğu gözlendi $(p<0,01)$. 
Tablo 2. Yaş gruplarına göre komplikasyon gelişimi.

\begin{tabular}{lcc}
\hline Yaş & $\mathbf{n}$ & Komplikasyon \\
\hline$<40$ yaş & 25 & $\% 12(n=3)$ \\
$\geq 40$ yaş & 25 & $\% 48(n=12)$ \\
\hline
\end{tabular}

Çalışmamızda VKi, eksize edilen meme dokusu ağırlığı ve preoperatif HAM-D ve HAM-A puanları ile komplikasyon gelişimi arasındaki korelasyonlar incelendiğinde, VKi ile komplikasyon gelişimi arasında istatistiksel olarak anlamlı ilişki gözlenmedi $(p=0,231)$ (Tablo 3). Eksize edilen meme dokusu miktarı 3000 g'dan az olan hasta grubu ile eksize edilen meme dokusu miktarı 3000 g'dan fazla olan hasta grubu arasında komplikasyon gelişimi açısından istatistiksel olarak anlamlı farklılık gözlenmedi ( $p=0,662)$ (Tablo 4).

Tablo 3. Vücut kitle indeksine göre komplikasyon gelişimi.

\begin{tabular}{lcc}
\hline Vücut kitle indeksi & $\mathbf{n}$ & Komplikasyon \\
\hline $25-30 \mathrm{~kg} / \mathrm{m}^{2}$ & 9 & $\% 11,1(\mathrm{n}=1)$ \\
$30-35 \mathrm{~kg} / \mathrm{m}^{2}$ & 22 & $\% 27,3(\mathrm{n}=6)$ \\
$>35 \mathrm{~kg} / \mathrm{m}^{2}$ & 19 & $\% 42,1(\mathrm{n}=8)$ \\
\hline
\end{tabular}

Tablo 4. Eksize edilen meme dokusu ağırlığına göre komplikasyon gelişimi.

\begin{tabular}{lcc}
\hline Eksize edilen meme dokusu ağırı̆ı $(\mathbf{g})$ & $\mathbf{n}$ & Komplikasyon \\
\hline$<3000 \mathrm{~g}$ & $29(\% 58)$ & $\% 27,6(\mathrm{n}=8)$ \\
$\geq 3000 \mathrm{~g}$ & $21(\% 42)$ & $\% 33,3(\mathrm{n}=7)$ \\
\hline
\end{tabular}

Çalışmamızda 22 hastada (\%44) HAM-D puanı 7'nin altında (depresyon yok) iken, 28 hastada (\%56) çeşitli derecelerde depresyon belirtileri olduğu saptandı (Tablo 5). On üç hastada ağır derecede depresyon, 8 hastada hafif, 7 hastada orta derecede depresyon bulguları gözlendi. Depresyon bulguları olan $(n=28)$ ve depresyon bulguları olmayan ( $n=22$ ) olan hasta grupları arasında komplikasyon gelişimi açısından istatistiksel olarak anlamlı farklılık gözlenmedi $(p=0,32)$.

Tablo 5. HAM-D ölçeği puanlarına göre komplikasyon gelişimi.

\begin{tabular}{lcl}
\hline HAM-D puanı & $\mathbf{n}$ & Komplikasyon \\
\hline 0-7 ( Depresyon yok) & $22(\% 44)$ & $\% 22,7(n=5)$ \\
8-53 (Depresyon var) & $28(\% 56)$ & $\% 35,7(n=10)$ \\
\hline
\end{tabular}

Çalışmamızda 16 hastada (\%32) HAM-A puanı 0-5 arasında (anksiyete yok) iken, 34 hastada (\%68) çeşitli derecelerde anksiyete belirtileri olduğu gözlendi (Tablo 6). On yedi hastada minor anksiyete, 17 hastada major anksiyete bulguları gözlendi. Preoperatif anksiyete bulguları olan ( $n=34)$ ve anksiyete bulguları olmayan ( $n=16)$ hasta grupları arasında komplikasyon gelişimi açısından istatistiksel olarak anlamlı farklııı gözlenmedi $(p=0,597)$.

Tablo 6. HAM-A ölçeği puanlarına göre komplikasyon gelişimi.

\begin{tabular}{lcc}
\hline HAM-A puanı & $\mathbf{n}$ & Komplikasyon \\
\hline 0-5 ( Anksiyete yok) & $16(\% 32)$ & $\% 25(n=4)$ \\
6-56 (Anksiyete var) & $34(\% 68)$ & $\% 32,4(n=11)$ \\
\hline
\end{tabular}

Preoperatif depresyon bulguları olan $(n=28)$ ve depresyon bulguları olmayan $(n=22)$ hasta grupları arasında hastanede yatış süreleri açısından istatistiksel olarak anlamlı farklılık gözlendi (Tablo 7) ( $p<0,001)$.

Tablo 7. HAM-D ölçeği puanlarına göre hastanede yatış süreleri.

\begin{tabular}{lccc}
\hline HAM-D puanı & $\mathbf{n}$ & $\begin{array}{c}\mathbf{0 - 6} \text { gün } \\
\text { hastanede } \\
\text { yatı̧ }\end{array}$ & $\begin{array}{c}\mathbf{7} \text { gün ve üzeri } \\
\text { hastanede } \\
\text { yatış }\end{array}$ \\
\hline 0-7 (Depresyon yok) & $22(\% 44)$ & $\mathrm{n}=16(\% 72,7)$ & $\mathrm{n}=6(\% 21,4)$ \\
$8-53$ (Depresyon var) & $28(\% 56)$ & $\mathrm{n}=6(\% 27,3)$ & $\mathrm{n}=22(\% 78,6)$
\end{tabular}

Preoperatif anksiyete bulguları olan $(n=34)$ ve anksiyete bulguları olmayan $(n=16)$ hasta grupları arasında hastanede yatış süreleri açısından istatistiksel olarak anlamlı farklılık gözlendi (Tablo 8) $(p<0,01)$.

Tablo 8. HAM-A ölçeği puanlarına göre hastanede yatış süreleri.

\begin{tabular}{lccc}
\hline HAM-A puanı & $\mathbf{n}$ & $\begin{array}{c}\mathbf{0 - 6} \text { gün } \\
\text { hastanede } \\
\text { yatış }\end{array}$ & $\begin{array}{c}\mathbf{7} \text { gün ve üzeri } \\
\text { hastanede } \\
\text { yatış }\end{array}$ \\
\hline $0-5$ (Anksiyete yok) & $16(\% 32)$ & $\mathrm{n}=12(\% 75)$ & $\mathrm{n}=4(\% 25)$ \\
6-56 (Anksiyete var) & $34(\% 68)$ & $\mathrm{n}=10(\% 29,4)$ & $\mathrm{n}=24(\% 70,6)$
\end{tabular}

\section{TARTIŞMA}

Küçültme mammoplasti memelerin aşırı büyüklüğüne bağlı meme ağrısı, sırt ağrısı, boyun ağrısı, omuz 
ağrısı, sütyen askısı basısına bağlı omuzlarda çöküklük, intertriginöz kızarıklıklar, postür değişiklikleri ve spor yapmada zorluklar gibi yakınmalarla başvuran hastalarda giderek daha sık yapılan bir plastik cerrahi operasyonudur. Çeşitli retrospektif ve prospektif çalışmalar makromastili kadınlarda redüksiyon mammoplastiden sonra bu semptomlarda önemli iyileşmeler ve yüksek hasta memnuniyetinin olduğunu bildirmiştir ${ }^{16-19}$.

Makromastili kadınlar sıklıkla aşırı kilolu veya obezdir. Makromastili hastalarda yüksek postoperatif komplikasyon oranlarının nedeni olarak sıklıkla obezite görüldüğü için plastik cerrahlar bu hastaları ameliyat etmekten kaçınırlar ${ }^{1,2}$. Bu hastalara ameliyat edilebilmeleri için kilo vermeleri gerektiği belirtilmesine rağmen, makromastinin ve aşırı kiloların sebep olduğu fiziksel aktivite azlığına bağlı spor yapmaktaki zorluklar çoğu kez hastaların preoperatif kilo vermelerini olası kılmaz. Bu nedenle çoğu kez bu hastalar gelişebilecek komplikasyonlar ve uzun sürebilecek tedavi aşamalarını kabul ettikleri durumlarda ameliyat edilirler. Daha az sıklıktaki yayınlarda ise obez hastalarda komplikasyon oranlarının artmadığı da belirtilmiştir ${ }^{20-22}$.

Ayrıca aşırı kilolu ve obez hastaların estetik kaygının yanında yaşam kalitesini düşüren ağrı, anksiyete ve depresyon gibi yakınmaları olduğu ve kadınlarda meme hacmindeki artış ile depresyon semptomları arasında ilişki olduğu bildirilmiştir ${ }^{3-5}$. Çoğu kez fiziksel semptomlardan daha yıkıcı olabilen bu emosyonel yakınmalar hastaların içe kapanmalarına, toplumdan kopmalarına ve daha fazla kilo almalarına neden olabilir. Bu hastaların bir kısmı psikiyatri klinikleri tarafından kendilerine verilen antidepresan ilaçları kullanırlar. Ancak bu hastalar antidepresan ilaçları kullanmalarına rağmen, bu emosyonel semptomların kökeninde makromastinin fiziksel semptomları olduğu için emosyonel semptomlarında rahatlama olmayabilir. Küçültme mammoplasti sonrası bu semptomlarında rahatlama olması beklenebilir. Iwuagwu ve ark.'nın ${ }^{23}$ yaptığı çalışmada, anksiyete ve depresyonu olan makromastili hastalarda meme küçültme cerrahisi sonrası anksiyete ve depresyonda anlamlı de- recede azalma olduğu ortaya konmuştur. Küçültme mammoplasti uygulanan kadınların $1 / 3$ 'inde operasyondan önce anksiyete, depresyon ve beden saygısında azalma olduğu ve cerrahi sonrası depresyon düzeyinde azalma olduğu bildirilmiştir ${ }^{6-9}$.

Aşırı kilolu ve obez hastalarda küçültme mammoplasti makromastinin fiziksel ve emosyonel semptomlarında dramatik iyileşmeler sağlar. Ancak cerrahi öncesi hastalarda depresyon, anksiyete gibi emosyonel sorunların ya da semptomların olmasının, cerrahi sonrası iyileşmenin daha yavaş olmasına, komplikasyon oranlarının artmasına ve cerrahinin sonucundan memnun kalmamaya yol açtığı gösterilmiştir ${ }^{10-11}$. Estetik amaçlı meme küçültme cerrahisi uygulanan kadınlarda preoperatif depresyon ve anksiyete düzeylerini inceleyen çalışmalar olmakla birlikte, literatürde semptomatik makromastili aşırı kilolu veya obez kadınlarda küçültme mammoplasti öncesi depresyon ve anksiyete düzeylerinin postoperatif yara iyileşme komplikasyonlarının gelişimi üzerine etkilerini inceleyen yeterli çalışmaya rastlanmamıştır.

Çalışmamızda aşırı kilolu ve obez hastalarda preoperatif depresyon ve anksiyete düzeyleri ile küçültme mammoplasti sonrası yara iyileşme komplikasyonları ve hastanede yatış süreleri arasındaki ilişkiyi değerlendirmeye çalıştık.

Çalışmamızda, HAM-D ölçeği puanları ortalamasının ameliyat öncesi 14,74 $\pm 12,54$ olması hastaların ameliyat öncesi hafif derecede depresyona sahip olduğunu düşündürmüştür. Çalışmamızın bulgularına yakın olarak Meningaud ve ark.'nın ${ }^{24}$ yaptığı sistematik incelemede estetik cerrahi öncesi hastalarda orta düzeyde distres belirtileri olduğu bildirilmiştir. Çalışmadaki hastaların \%6,5'inde depresyon puanlarının yüksek olduğunun görülmesi nedeniyle estetik cerrahi girişimi öncesinde hastaların psikolojik açıdan değerlendirilmesinin önemi vurgulanmıştır.

Çalışmamızda, HAM-A ölçeği puanları ortalamasının ameliyat öncesi $12,30 \pm 9,62$ olması hastaların ameliyat öncesi minor anksiyeteye sahip olduğunu düşündürmüştür. 
Çalışmamızda VKI, çıkarılan meme dokusu ağırlığı, preoperatif HAM-D ve HAM-A ölçeği puanları ile komplikasyon gelişimi arasındaki ilişkiler incelendiğinde, VKi arttıkça hastalarda komplikasyon gelişimi istatistiksel olarak anlamlı olmayan bir şekilde artmaktaydı. Eksize edilen meme dokusu ağırlığı arttıkça komplikasyon gelişimi istatistiksel olarak anlamlı olmayan bir şekilde artmaktaydı. Preoperatif HAM-D ölçeği puanları yüksek olan hastalarda komplikasyon gelişimi artmakla birlikte bu artış istatistiksel olarak anlamlı değildi. Preoperatif HAM-A ölçeği puanları yüksek olan hastalarda komplikasyon gelişimi artmakla birlikte bu artış istatistiksel olarak anlamlı değildi.

Preoperatif HAM-D ölçeği puanları yüksek olan hastalarda hastanede yatış süresi istatistiksel olarak anlamlı şekilde yüksek gözlendi. Preoperatif HAM-A ölçeği puanları yüksek olan hastalarda hastanede yatış süresi istatistiksel olarak anlamlı şekilde yüksek gözlendi. Hastanede yatış sürelerinin yüksek olmasının başlıca nedeni gelişen minor komplikasyonların tedavisi olmuştur.

Çalışmamızın kısıtlıığı hasta sayısının az olmasıdır. Bununla birlikte, çalışmamız aşırı kilolu ve obez hastalarda bu konuda yapılmış nadir çalışmalardan birisidir. Daha homojen hasta gruplarını içeren daha büyük hasta populasyon ile yapılacak çalışmalarda preoperatif depresyon ve anksiyete düzeylerinin postoperatif yara iyileşme komplikasyonlarının gelişimindeki rolleri daha ayrıntılı olarak değerlendirilebilir.

\section{SONUÇ}

Çalışmamız meme küçültme ameliyatı olmak için başvuran semptomatik makromastili, aşırı kilolu ve obez hastaların preoperatif dönemde hafif derecede depresyona ve minor anksiyeteye sahip olduklarını göstermiştir. Hastalarda preoperatif depresyon ve anksiyete düzeyleri arttıkça postoperatif yara iyileşme komplikasyonları da istatistiksel olarak anlamlı olmayan bir şekilde artmıştır. Bu hastalarda cerrahi planlanırken postoperatif komplikasyon gelişme riskini artırabilecek iki patoloji olarak anksiyete ve depresyon düzeyleri göz önünde bulundurulmalıdır. Semptomatik makromastili hastaları perioperatif süreç boyunca fiziksel sağlıkları yanında emosyonel açıdan da değerlendiren daha büyük hasta populasyonu içeren daha kapsamlı çalışmaların yapılması gerekmektedir. Bu değerlendirmeler için psikiyatrik tanılar yeterli olmayabilir, bu alanda daha çok objektif veriye gereksinim vardır.

Teşekkür: Çalışmanın istatistiksel değerlendirmelerinde yardımcı olan Yrd. Doç. Dr. Birol TOPÇU'ya teşekkür ederim.

\section{KAYNAKLAR}

1. Gamboa-Bobadilla GM, Killingsworth C. Large-volume reduction mammaplasty: The effect of body mass index on postoperative complications. Ann Plast Surg 2007;58:246-249. http://dx.doi.org/10.1097/01.sap.0000248108.52837.6c

2. Zubowski R, Zins JE, Foray-Kaplon A, et al. Relationship of obesity and specimen weight to complications in reduction mammaplasty. Plast Reconstr Surg 2000;106:998-1003. http://dx.doi.org/10.1097/00006534-200010000-00006

3. Saariniemi KM, Joukamaa M, Raitasalo $R$, et al. Breast reduction alleviates depression and anxiety and restores selfesteem: a prospective randomised clinical trial. Scand J Plast Reconstr Surg Hand Surg 2009;43:320-4. http://dx.doi.org/10.1080/02844310903258910

4. Benditte-Klepetko H, Leisser V, Paternostro-Sluga $T$, et al. Hypertrophy of the breast: a problem of beauty or health? J Womens Health 2007;16:1062-9. http://dx.doi.org/10.1089/jwh.2006.0183

5. Herva A, Laitinen J, Miettunen J, et al. Obesity and depression: results from the longitudinal Northern Finland 1966 Birth Cohort Study. Int J Obes 2006;30:520-7. http://dx.doi.org/10.1038/sj.ijo.0803174

6. Saariniemi KM, Joukamaa M, Raitasalo R, et al. Breast reduction alleviates depression and anxiety and restores selfesteem: a prospective randomised clinical trial. Scand J Plast Reconstr Surg Hand Surg 2009;43:320-4. http://dx.doi.org/10.1080/02844310903258910

7. Benditte-Klepetko $H$, Leisser $V$, Paternostro-Sluga $T$, et al. Hypertrophy of the breast: a problem of beauty or health? J Womens Health 2007;16:1062-9. http://dx.doi.org/10.1089/jwh.2006.0183

8. Herva A, Laitinen J, Miettunen J, et al. Obesity and depression: results from the longitudinal Northern Finland Birth Cohort Study. Int J Obes 2006;30:520-7.

http://dx.doi.org/10.1038/sj.ijo.0803174

9. Guthrie E, Bradbury E, Davenport P, et al. Psychosocial status of women requesting breast reduction surgery as compared with a control group of large-breasted women. J Psychosom Res 1998;45:331-9. http://dx.doi.org/10.1016/S0022-3999(98)00002-6

10. Borah G, Rankin M, Wey P. Psychological complications in 281 plastic surgery practices. Plast Reconstr Surg 1999;104:1241-6.

http://dx.doi.org/10.1097/00006534-199910000-00002 
M. Çeber, May a correlation exist between preoperative depression and anxiety levels and wound healing complications following reduction mammoplasty in the overweight female?

11. Rankin M, Borah G. National plastic surgical nursing survey. Plast Surg Nurs 2006;26:178-83. http://dx.doi.org/10.1097/00006527-200610000-00004

12. Williams JB. Standardizing the Hamilton Depression Rating Scale: past, present, and future. Eur Arch Psychiatry Clin Neurosci 2001;251(Suppl 2):II6-12. http://dx.doi.org/10.1007/BF03035120

13. Akdemir A, Örsel S, Dağ i, ve ark. Hamilton Depresyon derecelendirme Ölçegi'nin (HDDÖ) geçerligi-güvenirligi ve klinikte kullanımı. Psikiyatri Psikoloji Psikofarmakoloji Dergisi 1996;4:251-259.

14. Hamilton $\mathrm{M}$. The assessment of anxiety states by rating. $\mathrm{Br} \mathrm{J}$ Med Psychol 1959;32:50-55. http://dx.doi.org/10.1111/j.2044-8341.1959.tb00467.x

15. Yazıcı MK, Demir B, Tanrıverdi N, ve ark. Hamilton anksiyete degerlendirme ölçegi, degerlendiriciler arası güvenirlik ve geçerlik çalısması. Türk Psikiyatri Dergisi 1998;9:114-117.

16. O' Blenes C, Delbridge C, Miller B, et al. Prospective study of outcomes after reduction mammoplasty: long-term followup. Plast Reconstr Surg 2006;117:351-358. http://dx.doi.org/10.1097/01.prs.0000201493.76256.65

17. Blomqvist L, Lennart MD, Brandberg Y. Three-year follow-up on clinical symptoms and health-related quality of life after reduction mammaplasty. Plast Reconstr Surg 2004;14:4954. http://dx.doi.org/10.1097/01.PRS.0000127794.77267.14

18. Chao JD1, Memmel HC, Redding JF, et al. Reduction mammaplasty is a functional operation, improving quality of life in symptomatic women: a prospective, single-center breast reduction outcome study. Plast Reconstr Surg 2002;110(7):1644-1652.

http://dx.doi.org/10.1097/00006534-200212000-00003

19. Rogliani M, Gentile P, Labardi L, et al. Improvement of physical and psychological symptoms after breast reduction. J Plast Reconstr Aesthet Surg 2009;62:1647-1649. http://dx.doi.org/10.1016/j.bjps.2008.06.067

20. Wagner DS, Alfonso DR. The influence of obesity and volume of resection on success in reduction mammaplasty: an outcomes study. Plast Reconstr Surg 2005;115:1034-1038. http://dx.doi.org/10.1097/01.PRS.0000154213.06888.F9

21. Setala L, Papp A, Joukainen S, et al. Obesity and complications in breast reduction surgery: are restrictions justified? J Plast Reconstr Aesthet Surg 62:195-199. http://dx.doi.org/10.1016/j.bjps.2007.10.043

22. Kendall K, Craig ES, Gomez V, Phillips LG. Breast reduction: safe in the morbidly obese? Plast Reconstr Surg 2008;122:370378.

http://dx.doi.org/10.1097/PRS.0b013e31817d60f4

23. Iwuagwu OC, Stanley PW, Platt AJ, et al. Effects of bilateral breast reduction on anxiety and depression: results of a prospective randomised trial. Scand J Plast Reconstr Surg Hand Surg 2006;40(1):19-23. http://dx.doi.org/10.1080/02844310500415335

24. Meningaud JP, Benadiba L, Servant JM, et al. Depression, anxiety and quality of life among scheduled cosmetic surgery patients: multicentre prospective study. J Craniomaxillofac Surg 2001;29(3):177-80. http://dx.doi.org/10.1054/jcms.2001.0213 